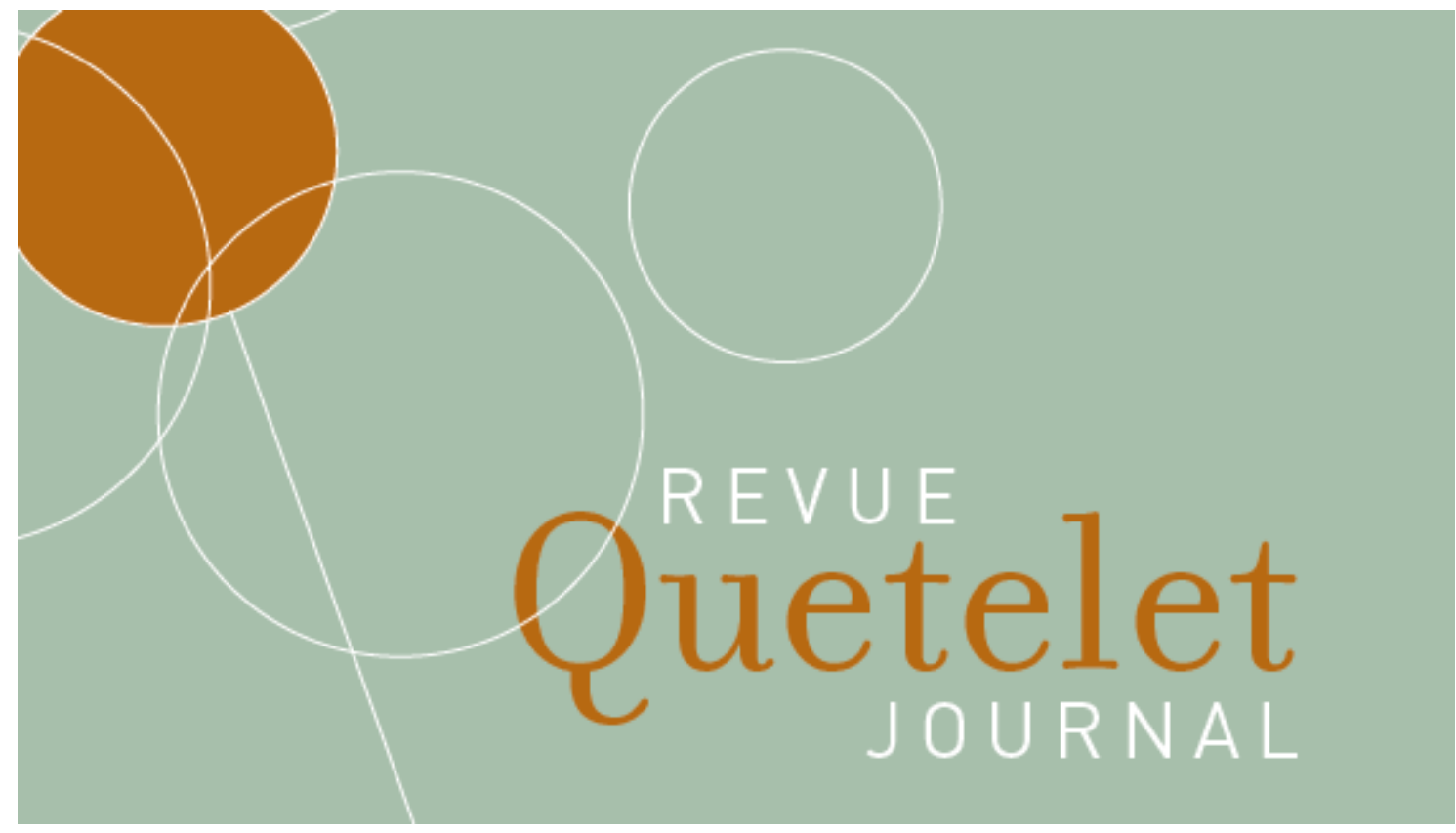

Vol. 8, $\mathrm{n}^{\circ} 1,2020$, pp. 7-35

DOI : $10.14428 /$ rqj2020.08.01.01

ISSN: 2593-9157

\title{
The Democratic Republic of the Congo armed conflict 1998-2004: Assessing excess mortality based on factual and cournter-factual projection scenarios
}

Richard Kapend, Jakub Bijak, Andrew Hinde

\section{(c) $\underset{\mathrm{BY}}{\mathrm{i} \text { () }}$}

(C2020 Richard Kapend, Jakub Bijak, Andrew Hinde

This work is licensed under a Creative Commons Attribution-NonCommercial 4.0 International License. You can share, adapt the material for non-commercial purposes provided that you give appropriate credit and indicate if changes were made. For details see https://creativecommons.org/licenses/by-sa/4.0/

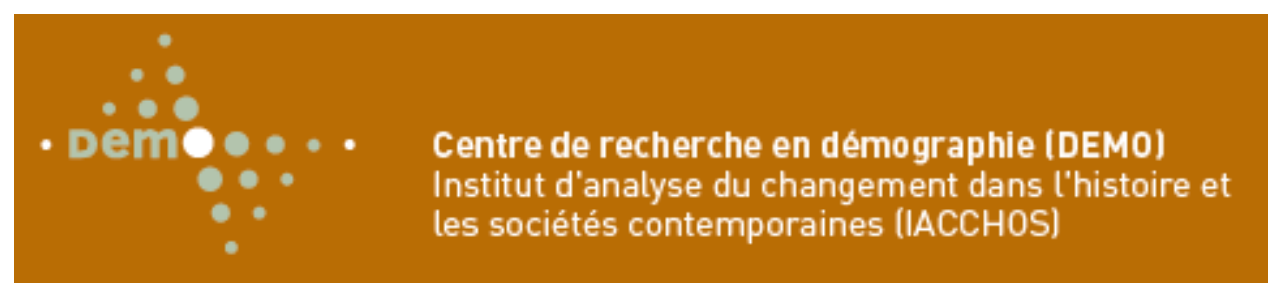





\title{
The Democratic Republic of the Congo armed conflict 1998-2004: Assessing excess mortality based on factual and cournter-factual projection scenarios
}

\author{
RICHARD KAPEND ${ }^{1}$ \\ JAKUB BIJAK ${ }^{2}$ \\ ANDREW HINDE ${ }^{2}$
}

\begin{abstract}
Résumé
Pour documenter l'ampleur et la portée des conflits armés de 1998 à 2004 en République démocratique du Congo (RDC), la présente étude a combiné quatre sources de données différentes : le recensement de la population de la RDC de 1984, les enquêtes en grappes à indicateurs multiples de 1995 et 2001 et l'enquête démographique et sanitaire de 2007, afin de reconstruire les estimations démographiques manquantes et d'évaluer le niveau de surmortalité associé au conflit, de 1998 à 2007. Les résultats de cette étude ne corroborent pas les estimations précédentes sur le même conflit armé et pour la même période : celles-ci vont d'une surmortalité de 5,4 millions d'habitants selon Coghlan et al. (2009), à 0,2 million selon Lambert et LohléTart (2008).

La méthode de projection par composantes de cohorte utilisée dans cette étude est une approche rentable car elle permet d'analyser une question complexe, à savoir la surmortalité associée à un conflit armé, avec des ressources relativement modestes. Cette étude souligne que le choix des taux de base est un facteur clé pour déterminer le niveau de surmortalité lorsque les points de données sont rares. Cette étude a produit une gamme d'estimations plausibles de la surmortalité entre 1 et 1,9 million de personnes plutôt qu'une seule meilleure estimation. La fourchette de surmortalité produite dans cette étude est plus étroite et moins extrême par rapport aux études précédentes sur le même conflit. Comme contribution supplémentaire au débat
\end{abstract}

\footnotetext{
1. University of Portsmouth, United Kingdom.

2. University of Southampton, United Kingdom.
} 
dans ce domaine, la présente étude préconise de produire une gamme d'estimations plausibles plutôt qu'une seule meilleure estimation de la surmortalité. Cela se justifie par les incertitudes liées à la rareté des données, à la modélisation statistique et au processus d'analyse global.

\title{
Mots-clé
}

République démocratique du Congo, conflit armé, évolution de la population, surmortalité, reconstructions basées sur des projections.

\begin{abstract}
To document the scale and scope of the 1998-2004 armed conflicts in the Democratic Republic of the Congo (DRC), the current study combined four different data sources: the 1984 DRC Population Census, the 1995 and 2001 DRC Multiple Indicator Cluster Surveys and the 2007 DRC Demographic and Health Survey, to reconstruct missing demographic estimates and assess the level of excess mortality associated with the conflict, going from 1998 to 2007. Findings from this study do not corroborate previous estimates on the same armed conflict and for the same period: these range from excess mortality of 5.4 million population according to Coghlan et al. (2009), to 0.2 million according to Lambert and Lohlé-Tart (2008).

The cohort component projection method as used in this study is a cost-effective approach as it allows the analysis of a complex issue, that is excess mortality associated with an armed conflict, with relatively modest resources. This study highlights that the choice of baseline rates is a key factor in determining the level of excess mortality when data points are scarce. This study produced a range of plausible estimates of excess mortality between 1 and 1.9 million population rather than a single best estimate. The range of excess mortality produced in this study is narrower and less extreme when compared to previous studies on the same conflict. As a further contribution to the debate in this field, the current study advocates producing a range of plausible estimates rather than a single best estimate of excess mortality. This is justified by the uncertainties associated with the scarcity of the data, the statistical modelling and the overall analysis process.
\end{abstract}

\section{Keywords}

Democratic Republic of the Congo, armed conflict, population change, excess mortality, projection-based reconstructions.

\section{Introduction}

The overarching objective of this paper is to analyse the demographic consequences of the 1998-2004 conflict in the Democratic Republic of the Congo (DRC). An armed conflict and the violence associated with it have significant demographic consequences, which in turn can lead to a wide range of other social and economic implications (Urdal, 2012, p. 130; 
Matthew, 2012, p. 140). These demographic consequences can be assessed over time and space for all three components of population change: mortality, fertility and migration (Brunborg, Tabeau, 2005, pp. 36). It is worth noting that assessing the extent of excess mortality is particularly challenging in the case of the DRC; where there is a significant lack of vital statistics or indeed a data management culture. For this and many other reasons, only a limited number of studies have, so far, researched the extent of mortality associated with the DRC armed conflict.

Studies specifically looking at the consequences of armed conflict on mortality have used terms including: «excess deaths» and/or «excess mortality» to describe the number of deaths that occurred to a given population over and above the number to be expected in the absence of the conflict (Heuveline, 1998; Burnham et al., 2004; Lambert, Lohlé-Tart, 2008). The analytical framework adopted in the current study derives excess mortality as one of the three components of the overall population change. In other words, the current study considered not only mortality, but also the potential impact that could be attributed to fertility and forced migration during the considered period.

To achieve its overarching aim, the current paper seeks to inform policy and promote peace in a post-armed conflict situation. The primary purpose of the current paper is not to engage in a kind of comparison of mortality estimates contest with previous studies on this topic, including Roberts et al. (2003), Lambert and Lohlé-Tart (2008) and Coghlan et al. (2009), which assessed the extent and scope of excess mortality associated with the 1998-2004 DRC armed conflict. Estimates of mortality derived from the current study can, to a certain extent, lend themselves to comparison with those from previous studies. Such comparison is not intended as the main purpose of the current paper but would nevertheless contribute to extending the debate on this topic. This is even more important, as the previous studies produced contrasting estimates of war-induced mortality (see Human Security Report, 2011, and Sciencemag, 2010, for reviews), and there is still no clear evidence on which of the previous estimates is closer to the truth.

This paper is organised as follows: the first section presents the rationale behind this study, the second section provides a background to the DRC armed conflict, the third section discusses previous work on excess mortality associated with the DRC armed conflict, the fourth section introduces the data and methods used to derive the needed estimates, whereas the fifth section presents and discusses findings, and the last section explores some of the implications before drawing conclusions. 


\section{Rationale}

This study refers to the following two periods: 1998-2004 and 19982007. The first one (1998-2004) represents the period of the DRC armed conflict, which ended following a peace agreement signed in 2003 between different factions involved that led to the formation of a coalition government in the DRC in 2005 and a constitutional referendum in 2006 (Participants, Democratic Republic of the Congo 2003). The second one (1998-2007) refers to the period over which the demographic impact of the conflict is assessed. The second period (1998-2007) was set out to provide practical measurable reference points, but also to allow comparisons with the existing studies of Lambert and Lohlé-Tart (2008) and Coghlan et al. (2009), as they both used the 1998-2007 period to estimate excess mortality associated with the DRC conflict.

Earlier studies on this topic seem to have focussed on producing a single «best» estimate of war-induced mortality rather than a range of plausible estimates, disregarding the prospect of any uncertainty associated with the data and the analysis process. Both Lambert and Lohlé-Tart (2008) and Coghlan et al. (2009) produced their excess mortality figures without taking into account any uncertainty associated with both the assumptions made and the data used to derive the estimates of interest. The current paper used an alternative approach exploring two scenarios: factual and counter-factual, for selected sets of DRC population data combined under a set of plausible assumptions (Heuveline, 1998).

In particular, any estimates of the excess mortality associated with armed conflicts are controversial. Often, this is due to various interests at play and the political sensitivities within which they tend to be wrapped. In this respect, producing single «best» figures as in Coghlan et al. (2009) or in Lambert and Lohlé-Tart (2008) might unwittingly contribute to extending the controversy. The uncertainties associated with both the assumptions and the data used to conduct a comprehensive assessment of demographic consequences associated with armed conflict justify the need for a method that allows the production of a range of plausible estimates (Heuveline, 1998, 2015, pp. 205-208).

\section{Background to the conflict}

The origin of the DRC armed conflict can be traced back to both internal and external causes. 


\section{Internal causes}

The DRC has experienced continued periods of instability and conflict since becoming an independent state in 1960. Soon after independence, the situation in the country was characterised by violence and the proliferation of rebel groups vying for both political power and economic domination. By the mid-1960s, following a military coup led by Mobutu Sese Seko, the country saw a gradual improvement in security. From the late 1960 s to the late 1970 s the country was marked by relative stability that enabled economic growth and an overall improvement in the lives of many Congolese (Nzongola-Ntalaja, 1970).

Despite going through a period of apparent stability from the mid-1960s, one of the most brutal dictatorships on the African continent also started to take hold of the country. The Mobutu regime indulged in poor governance and the shutting down of political space. From the early 1980s, growing pressure both inside and outside the country led the regime gradually to open up the political space by allowing a multi-party system and more freedom for the press. However, this process was plagued with delays and failed promises that led to further chaos and growing frustration. By the early 1990s a sense of generalised crisis was widely perceptible, casting serious doubt about the viability of the country as a fully functioning state (Naniuzeyi, 1999; Nzongola-Ntalaja, 2002). The vulnerabilities that characterised the country in the 1990s culminated in a civil war that saw Congolese rebels led by Laurent Désiré Kabila and his allies overthrow the Mobutu regime in 1997.

Under the Mobutu regime and the years leading to the armed conflict covered in this paper, the quality of life for the Congolese deteriorated. The kleptocratic character of the regime and its mismanagement of public resources meant that public servants were unpaid for several months, if not years. To make ends meet, many members of the armed forces and the police preyed on civilians in violation of the latter's basic human rights (Human Rights Watch, 1998; Research Directorate, Immigration and Refugee Board, Canada, 1997). Public services were performed on the basis of bribery and kickbacks. During the Mobutu regime the country accumulated a public external debt of roughly $\$ 14$ billion whilst Mobutu and his ruling class extracted wealth from the country. By 1990, real capital flight from Zaïre, as the country was known between 1971 and 1997, was estimated at $\$ 12$ billion (Ndikumana, Boyce, 1998, p. 199). The educational and health systems were neglected, leading to a growing shortage of skills. Out-migration, both to other African countries and to Europe, was common, fuelled by a lack of opportunities within the DRC 
and the increase in opportunities elsewhere, as those with skills wanted to migrate to places where conditions were more conducive to their aspirations (Flahaux, Schoumaker, 2016).

The vulnerabilities of the economy and politics paved the way for a set of internal struggles that contributed to the onset and development of the armed conflict covered in this paper. Beside the state of collapse in which the country was at the onset of the armed conflict in the late 1990s, a number of external factors played a determinant role in triggering and exacerbating the conflict.

\section{External causes}

From a different angle, the armed conflict can be seen as the result of a spill-over from the 1994 civil war that culminated in the Rwandan genocide (United Nations Security Council, 1994). Faced with a generalised crisis following many years of poor governance and mismanagement, a sudden influx of around 1.5 million refugees fleeing civil war in Rwanda (United Nations High Commission for Refugees, 1998; Verpoorten, 2005), proved too much for the Zaïre regime to cope with. Among those fleeing Rwanda were Hutu extremists and defeated members of the then Rwandan army. These groups managed to cross into Zaïre with their military apparatus and command structure intact (Prunier, 2009).

The presence of Rwandan refugees and the uncontrolled circulation of weapons of war in eastern Zaïre gave rise not only to a severe humanitarian crisis, but also to diplomatic tensions which led to a military escalation between Zaïre and the new regime in Rwanda. In 1996, with the aim of neutralising threats posed by Hutu extremists and remnants from the defeated Rwandan army, the regime in Kigali formed an alliance with Congolese rebels and other neighbouring countries including Uganda and Burundi to start a military campaign in eastern Zaïre (Reyntjens, 1999). During this military campaign, different members of the alliance pursued their own goals and objectives. The Rwandan regime set out to eradicate threats posed by the Democratic Front for the Liberation of Rwanda formed of Hutu extremists and remnants from the defeated/previous Rwandan regime; Ugandan armed forces targeted the Allied Democratic Forces, a rebel group opposed to the Ugandan government and considered by the latter to be a terrorist organisation; and the Burundian army sought this opportunity to neutralise the rebel Force for the Defence of Democracy (Prunier, 2009). 
By late May 1997, and despite pursuing different interests, the forces that formed the alliance managed to overthrow the Mobutu regime and partially to neutralise the various rebel groups that posed threats to member states within the alliance. By 1998, a deterioration in relations between the new regime in the country, renamed Democratic Republic of the Congo (DRC), and other members of the alliance led to the 1998 war. The new leader in the DRC (Laurent Désiré Kabila) fell out with his key allies the leaders of Rwanda (Paul Kagame) and Uganda (Yoweri Museveni) prompting a new and more complex armed conflict involving more than six different nations and dozens of armed groups and dozens of local militias (International Crisis Group, 1998). At its most critical stage, the conflict saw the country being divided into three different areas administered by three different warring factions whilst the central government held the capital city Kinshasa and the major parts of the mineral rich Katanga province. However, by 2004, a combination of pressure and sanctions from the United Nations, regional players, and the international community as well as internal dynamics led to a settlement that paved the way to a progressive return to peace. Key protagonists agreed to a power sharing agreement that allowed the adoption of the new constitution in 2005 and subsequently the organisation of the first democratic elections since 1960s. Nevertheless, there are still, as of November 2019, armed groups operating in pockets of insecurity and numerous human right abuses, especially in the eastern part of the country (Stearns et al., 2013; United Nations News, 2019).

\section{Previous work on the demographic impact of the conflict}

\section{Population change or excess mortality?}

Existing studies of the demographic impact of the conflict have looked at excess mortality or excess deaths (Coghlan et al., 2009; Lambert, LohléTart, 2008). Population change can be defined as an analytical category that factors all three components of population change including births, deaths and migration. Hence, despite the focus on excess mortality, this paper endeavoured to put it in a wider context and examine the overall population change, both conceptually and practically. Conceptually, because it encompasses an analysis of births (or fertility), deaths (or mortality) and migration to estimate the overall demographic change (Hinde, 1998, p. 2) associated with the armed conflict; practically, because it al- 
lows the use of both factual and counter-factual scenarios when conducting population projections (Siegel, Swanson, 2008). It turns out that the net impact of the DRC armed conflict on population change through fertility and migration was not large during the considered period: excess mortality has been the main determinant component, allowing therefore, comparison with existing studies. The actual impact of both fertility and migration is discussed in the results section of this paper.

\section{Existing studies}

The only two existing studies to have investigated the demographic impact of the DRC armed conflict for the period 1998-2007 are those of the International Rescue Committee (IRC) (Roberts et al., 2003; Coghlan et al., 2006, 2009), and Lambert and Lohlé-Tart (2008)33. As a world-leading humanitarian organisation, the IRC is well known for monitoring crisis situations in developing countries. It is highly regarded by governments and non-governmental organisations around the world. Hence, the estimates of excess mortality produced by the IRC would be expected to be a significant factor in informing national and international policy on issues related to armed conflict and their effects on population (United Nations Office of the High Commissioner for Human Rights, 2010). However, despite its renowned humanitarian interventions, often in challenging settings, several methodological aspects of studies commissioned by the IRC on the demographic impact of armed conflict in the DRC are open to challenge.

Between 2000 and 2007 a series of five retrospective mortality surveys commissioned by the IRC were conducted in the DRC with the aim of assessing the extent and scope of excess mortality associated with the armed conflict for the period 1998-2007 (Roberts et al., 2003; Coghlan et al., 2006, 2009). The IRC's surveys were conducted in April and May 2000, March 2001, September and November 2002, April to July 2004 and May to July 2007. Two main concerns can be raised in relation to the IRC's overall approach and consequently the findings from these surveys (Sciencemag, 2010; Human Security Report, 2011).

- The IRC's earlier retrospective surveys used cluster samples mainly in elected health zones from areas affected by the armed conflict in eastern regions

3. This is an unpublished internal document that was mentioned in a number of newspapers including lalibre.be and lemonade.fr. It is available on the following link: http://adrass.net/WordPress/wp-content/uploads/2010/12/Surmortalite_en_RDC_19 98_2004.pdf [accessed 9 April 2020]. 
of the DRC. The results of these surveys were extrapolated to the national level to generalise findings (Coghlan et al., 2006, p. 46), even though much of the rest of the country was less affected by conflict.

- The IRC chose to use the average sub-Saharan crude death rate of 1.5 deaths per 1'000 population per month in the year 2004 as the baseline mortality. This baseline crude death rate was then compared against mortality rates generated from retrospective surveys for the conflict period of 2.1 deaths per 1'000 population per month. The difference between these two generated the excess deaths.

Although the IRC's last three surveys were conducted from clusters pulled at the national level, the fact that its first two were drawn from sub-national clusters known to be affected by the war, contributed to a very high estimate of excess mortality of 5.4 million population between 1998 and 2007 (Pedersen, 2009). The IRC's use of an average sub-Saharan crude death rate (CDR) per year of 1.5 as a baseline, which was then compared to that derived from the retrospective surveys of 2.1, is likely to have contributed to an overestimation of the derived estimate of excess mortality. A sub-Saharan CDR per year of 1.5 used by the IRC can be seen as relatively low even from a pre-conflict DRC perspective. In 1984, the DRC had a CDR per year close to 1.6 as recorded in the 1984 census (Institut National de la Statistique, 1994, p. 17). Given the deteriorating economic and political situation in which the country found itself from the mid-1980s, it can be argued that the crude death rate is unlikely to have decreased to 1.5; the opposite or an increase in CDR per year is highly likely.

Looking at the same conflict, Lambert and Lohlé-Tart (2008) raised similar concerns in relation to the IRC's choice of mortality baseline and the fact that estimates from sub-national clusters in health zones affected by war were generalised to the national level. Using a different approach, they produced a much lower estimate of the number of excess deaths of around 200'000 (in contrast to the 5.4 million produced by the IRC). Lambert and Lohlé-Tart (2008) projected the 1984 DRC population, as recorded in the census, to the year 2006 and matched it with the approximate DRC population size based on the adult population recorded in the 2006 voters' registration. The matching process consisted of comparing the size, and age and sex distribution between the projected adult population for the period 1998-2005 and the voters' registration of 2006. Lambert and Lohlé-Tart (2008) estimated the total number of excess 
deaths to be $405^{\prime} 759$. However, when they considered the fact that mortality during this period was not distributed evenly throughout the country, this number was revised down to $222^{\prime} 762^{4}$.

Lambert and Lohlé-Tart based most of their calculations and estimates on the 2006 voters' registration data. However, they were unable to make this data source available. Not being able to access Lambert and LohléTart's data makes it impossible effectively to assess their work or replicate their overall approach.

\section{FIGURE 1 Percentage of the total number of United Nations Security Council resolutions which concerned the Democratic Republic of the Congo between 1999 and 2014: total of 64 resolutions}

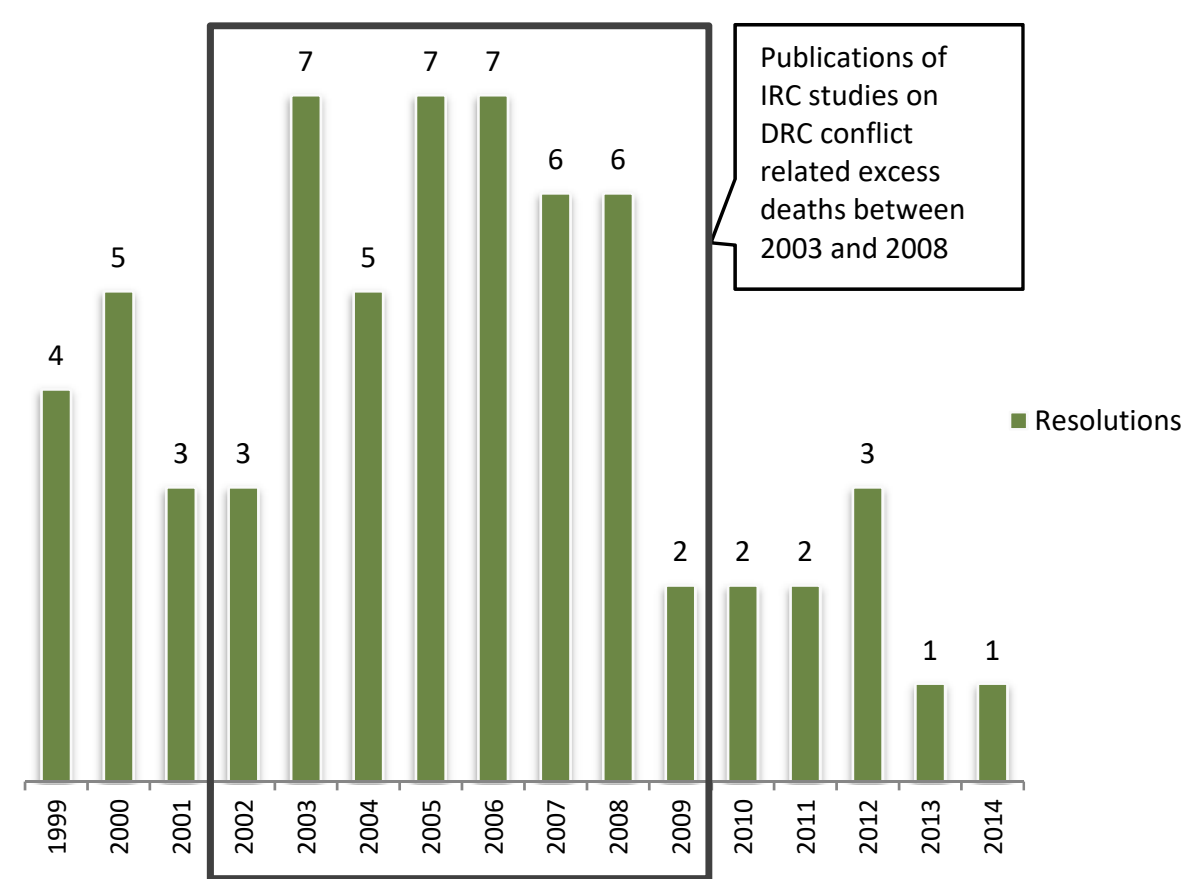

Source: Own estimation based on United Nations Security Council Resolutions on the Democratic Republic of the Congo adopted between 1999 and 2004.

The estimates of excess deaths can be influential, as they inform the policy of international organisations. Between the onset of the war in the DRC

\footnotetext{
4. http://adrass.net/WordPress/wp-content/uploads/2010/12/Surmortalite_ en_RDC_1998_2004.pdf, p. 17 [accessed 9 April 2020].
} 
in August 1998 and January 2014, the United Nations Security Council (UNSC) adopted 64 resolutions related to the conflict. As shown in Figure 1 above, the majority of the resolutions passed by the UNSC were adopted between 2003 and 2008, coinciding with the IRC's publication of a series of retrospective mortality surveys on the DRC conflict (United Nations Security Council, 1999a, 1999b, 2014). Of course, although there tends to be an association between the IRC's publication of the number of excess deaths associated with the conflict and the number of UNSC resolutions, causation cannot be assumed or evidenced in a meaningful manner. Several other contributing factors, such as a threat to regional peace and repeated violations of human rights are more likely to have influenced the UNSC's increased attention to the DRC. This is also more likely given the fragile situation that characterised the region in the aftermath of the Rwandan genocide of the mid-1990s.

\section{Data and methods}

Data

This paper combines selected DRC data sources including the latest census, held in 1984; two Multiple Indicator Cluster Surveys (MICS), MICS 1 in 1995 and MICS 2 in 2001; and the Demographic and Health Survey (DHS) of 2007. The census and surveys were used to derive demographic estimates and to reconstruct the dynamics of population change since 1984. Our approach compares two sets of scenarios: factual ones, based on our best estimates of what actually happened, and a counter-factual, based on a set of assumptions on how the population would have evolved in the absence of the 1998-2004 conflict. The study adopts an empirical approach, and its findings allow not only comparison with existing studies, such as Roberts et al. (2003) and Lambert and Lohlé-Tart (2008) but also a contribution to the literature on demographic consequences of armed conflict.

It is worth noting that the population of interest in the current study is constituted by individuals living in households found in the DRC at the time of the different surveys i.e. the 1995 MICS 1, the 2001 MICS 2 and the 2007 DHS. The DRC surveys only considered households drawn from exhaustive lists of inhabited plots in sampled neighbourhoods or dwellings in established villages (rural areas) and Wards (Quartier) in urban areas based on maps updated from the 1984 census (Ministère du 
Plan, Reconstruction Nationale RDC, 1995, pp.120-122; World Bank, 2018). Internally displaced persons (IDP) or refugees would not be includeed in this study or form a significant proportion of the population of interest (World Bank, 2018). More details of these surveys are provided in the data section below.

\section{General approach}

To estimate the excess mortality associated with armed conflict, several methods can be used (Brunborg, Tabeau, 2005). Commonly used methods include retrospective mortality surveys (Burnham et al., 2004; Kane, 2007), matching mortality records from various sources (Tabeau, Bijak, 2006), population projection under factual and counter-factual scenarios (Heuveline, 1998, 2015; Lambert, Lohlé-Tart, 2008), systematic counting of direct civilian casualties and the use of advanced technology to scan mass graves (Beswick, Minor, 2014) and statistical estimation based on multiple sources and multiple systems estimation methods (Price et al., 2014). As explained above, in this paper we use population projection under factual and counter-factual scenarios.

Borrowing from Heuveline's (1998) reconstruction of Cambodia's warrelated demographic estimates, this study used the cohort-component method of population projection and considered the assumption that an armed conflict affects all three components of population change. The cohort component method was deemed most appropriate because, contrary to previous studies that focused on mortality alone using retrospective mortality surveys (i.e. studies commissioned by the IRC), cohort component projection takes into account all three components of population change: births, deaths and migration (Siegel, Swanson, 2008) to estimate population dynamics associated with armed conflict throughout the considered projection period.

Some of the many reasons for adopting cohort component projection for this study include its mathematical ease of use which involves little more than basic arithmetic, accounting for historical inputs for births, deaths and migration to inform contingent but confident predictions of population dynamics over a given period. Cohort component projection also helps derive meaningful details of the age-sex composition and dynamics throughout the considered projection period (Burch, 2018, p. 137). It is also worth noting that cohort component projections, as opposed to bespoke surveys, are cost-effective, which allows studies with relatively modest resources such as the current one to conduct meaningful analyses on a complex topic. 
Despite some of its many strengths, cohort component projection has some limitations including the fact that its «standard algorithm is limited, linear, and 'open loop', and assumes continuity in fertility, mortality and migration» (Burch, 2018, p. 138).

In this study, this limitation was controlled by adjusting the projection intervals every five years using direct estimates from intermediate surveys. Despite some of the limitations, cohort component projection is a powerful and versatile analytic tool that allowed this study to produce not only estimates of population size that are consistent with those from alternative reputable sources: the United Nations Population Division (2013), the United States Census Bureau (2010), and the DRC's own office for national statistics (Institut National de la Statistique, 2014); but also a range of plausible estimates of excess mortality associated with the armed conflict.

Using 1984 as the projection's launch year, two sets of cohort component projections (factual and counter-factual) were conducted for a period of 30 years divided into five-year intervals. For each, four sets of assumptions were used:

- reference assumptions reflecting the baseline and average rates for each component of population change as captured in different data sources and at each of the benchmark years (1984, 1995, 2001 and 2007);

- «lower» assumptions designed to maximise excess mortality by applying the highest mortality rate, the lowest fertility rate and the highest net migration observed;

- «upper» assumptions designed to minimise excess mortality by applying the lowest mortality rate, the highest fertility rate and the lowest net migration observed for each benchmark year;

- mortality rates from the INDEPTH life tables were also used to conduct additional population projection exercises (INDEPTH Network 2004, pp. 9-36); assumptions based on the INDEPTH life tables provided the projections with mortality rates representing relevant mortality patterns in sub-Saharan Africa in recent years, taking into account the effect of the HIV/AIDS epidemic.

For each set of assumptions, the difference in population change between the factual and counter-factual scenarios as projected led to an estimate of excess mortality. Comparing the results obtained for various assumptions gave us an indication of the uncertainty surrounding the level of excess mortality. 


\section{Details of the method}

Panels (i) and (ii) of Table 1 summarise the use of the various data sources under the factual and counter-factual scenarios. Under the factual scenario we proceed as follows.

- The 1984 census data constitute the baseline for forward population projection to year 1995, using plausible assumptions based on vital rates recorded in the 1984 census. This census is also used to benchmark the first projection interval. The census information used to derive vital rates and support the population projection includes the age composition, the total fertility rate, the crude death rate, and the time lived at the current address.

- In 1995, MICS 1 survey-based estimates are introduced to benchmark the next part of the forward population projection up to the year 2001. In this projection for the factual scenario, the year 1995 is considered as being affected by war, because of the generalised crisis observed throughout the country (see the background to the conflict section for more detail) in the lead-up to the armed conflict. MICS 1 provided vital rates on births and deaths to benchmark the forward population projection between years 1995 and 2001.

- In 2001, MICS 2 estimates are introduced to provide vital rates on births and deaths to benchmark the next part of the forward population projection up to year 2007.

- In 2007 the DHS data are introduced to provide vital rates on births and deaths between 2007 and 2014.

TABLE 1 Democratic Republic of the Congo population reconstructions: summary of the main scenarios by projection horizons

\begin{tabular}{|c|c|c|}
\hline \multicolumn{3}{|c|}{ (i): Factual setting (real-world or war scenario) } \\
\hline Projection horizons & Data & Reconstruction operation \\
\hline 1984-1995 & Census & Forward projection to 1995 \\
\hline $1995-2001$ & MICS 1 & $\begin{array}{l}\text { Use MICS } 1 \text { estimates to adjust the } 1984 \text {-based projection, and } \\
\text { then project again to } 2001\end{array}$ \\
\hline 2001-2007 & MICS 2 & $\begin{array}{l}\text { Use MICS } 2 \text { estimates to adjust the projected 1995-adjusted pop- } \\
\text { ulation from and then project again to } 2007\end{array}$ \\
\hline 2007-2014 & DHS & $\begin{array}{l}\text { Use the DHS estimates to benchmark the projected rates, and } \\
\text { then project up to year } 2014\end{array}$ \\
\hline \multicolumn{3}{|c|}{ (ii): Counter-factual setting (non-war scenario) } \\
\hline 1984-2007 & Census & Forward projection to 2007 \\
\hline 2007-2014 & DHS & $\begin{array}{l}\text { Use the DHS estimates to adjust the } 1984 \text {-based projection and } \\
\text { project the population forward to } 2014\end{array}$ \\
\hline
\end{tabular}

Note: DHS, Demographic and Health Survey; MICS, Multiple Indicator Cluster Survey. 
Our assumption is that the periods 1995-2001 and 2001-2007 will show unusual trends in population dynamics due to the generalised crisis observed across the country throughout this period, including the spill over of the Rwandan civil war, the sudden influx of more than one million displaced persons fleeing from Rwanda, and the DRC armed conflict itself.

The counter-factual scenario (Table 1, panel (ii)) is simpler. The projection process is similar to the one introduced in panel (i) but here, the main assumption is that vital rates (fertility and mortality) recorded in 1984 converge to those recorded in the 2007 DHS on the basis of a linear change. The rates are then kept unchanged for the remainder of the population projection up to year 20145 .

For the forward population projection process, starting with the 1984 population size and composition, we proceeded in a series of five-year intervals, in each case calculating the number of persons alive at the beginning of the next projection interval. This was achieved in the usual manner, by adding the number of births over the same projection interval, deducting the number of deaths and adjusting for net international migration. We iterated this process six times for the factual and counterfactual scenarios until the end of the projection period in 2014. Different vital rates from selected assumptions were used to conduct a series of eight population projections: a factual and counter-factual scenario for each of the reference, «lower», and «upper» assumptions about vital rates and a factual and counter-factual scenario for the INDEPTH assumption about mortality was also conducted.

An aggregate mortality level taking into account HIV/AIDS prevalence was implemented in this study using the INDEPTH Model Life Tables for sub-Saharan Africa (INDEPTH, 2004). The model life table averaged estimates from both the Gwembe (Zambia) and Morogoro (Tanzania) sites, as they are more likely to share similar demographic changes to the Democratic Republic of Congo (DRC) than are any other INDEPTH sites in the region.

Despite having on average, a low HIV/AIDS prevalence of below 5\%, a detailed inspection shows that data on HIV/AIDS prevalence rates in DRC are very scanty. In particular, there are no consistent regional data within the country. Among women attending antenatal care clinics, for instance, the prevalence rate varied significantly from one area to another i.e.

5. Although estimates from the interval after 2007 are not a part of the conflict period under study (1998-2007), they help in the process of reconstructing a complete projection period of 30 years formed of six five-year projection intervals; starting from the 1984 census and ending in 2014. 
between $0.6 \%$ in Mikalayi (Kasaï province) and $10.8 \%$ in Kinshasa for the period 1992 and 1999. HIV sentinel surveys have not been conducted regularly and sites have not been used consistently (Dwyer-Lindgren et al., 2019). Since the Gwembe INDEPTH site has a high HIV/AIDS prevalence, and the Morogoro site has a low HIV/AIDS prevalence, the combination of the two can be supposed to have an «average» HIV/AIDS prevalence. Given the lack of regional data for the DRC, we feel this is the most sensible model to use (Unicef, 2004).

The difference between the factual and counter-factual scenarios resides in the fact that for the factual scenario, what actually happened (including the effect of conflict) is captured through vital rates from the intermediate surveys MICS 1 , and MICS 2 . With the counter-factual scenario, it is assumed the conflict did not take place and the forward population projection only considers the demographic conditions that prevailed at the census of 1984 and the DHS of 2007. In other words, the counter-factual scenario does not allow for actual demographic changes that may have taken place between 1984 and 2007.

Using cohort component projections, mortality estimates were derived from the census and surveys using indirect methods and selected model life table systems ${ }^{6}$. The 1995 MICS1 and the 2001 MICS 2 provided vital rates for children and women for the considered period. To reconstruct the missing male adult mortality rates, an extrapolation of children and women's mortality using the male age structure from the 1984 census was conducted. This was deemed the most appropriate way to reflect realistic population dynamics that prevailed for the periods around which the MICS and DHS surveys were carried out. To firm up the choice of these mortality rates, different standard model life tables were explored. To achieve this, pairs of survivorship probabilities, one from birth and another conditional on attaining a certain age, helped determine a set of survivorship estimates needed to create a complete life table (Newell 1988). From the observed survivorships at younger ages ( 0 to 19 years) and adult ages (20 years and above), as recorded in the census question on orphanhood, estimates of the proportions surviving to each age were derived using the Brass logit system (United Nations, 1983; Newell, 1988, pp. 151-166; Moultrie et al., 2013)7.

\footnotetext{
6. Model life tables are used for comparison in the assessment of empirical estimates of mortality, to minimise irregularities or otherwise adjust defective mortality estimates, and to complete the life table when estimates of mortality are available for only a limited range of ages.

7. For more details, see Kapend et al. (2013).
} 
To derive the harmonised total fertility rate (TFR) the current study used reported numbers of births per 1'000 by five-year age-groups of women aged from 15 to 49 years for the period 1985-1989 from Shapiro and Tambashe (2003, p. 55). These were harmonised with the mid-year total number of live births from women aged 15 to 49 years as recorded in the DRC 1984 Census. In other words, the current study used the 1984 Census to determine the level of fertility and the findings of Shapiro and Tambashe (2003) to determine the age distribution. Thus, the crude birth rate was estimated from the 1984 Census data. A ratio was calculated first by dividing the number of children enumerated aged under one year by the total enumerated population (Shapiro, Tambashe 2003). The calculated ratio was then adjusted to account for the children born in the year preceding the census who had died before the census date by dividing it by the number of infants aged under one year in a life table population with mortality equal to that of the 1980s in the DRC. ${ }^{8}$. Direct estimates of fertility found in more recent surveys including MICS 1, MICS 2 and the DHS, were then used under the factual scenario. Finally, age-specific fertility estimates from MICS $(1995,2001)$ and DHS (2007) were directly applied to the model to benchmark population projections, as shown in Table 1.

Estimates of net migration were obtained from the World Bank ${ }^{9}$. To achieve a better fit for age profiles this study proceeded as follows: first, we fitted a model schedule for total net migration counts; and, second, we derived age-specific net international migration figures to be used in cohort component projections. Age-specific migration volumes were estimated by making assumptions on key parameters following the approach proposed by Wilson (2010) and the accompanying curve-fitting tool. These were standardised by using proportions from the 1984 Census and 2007 DHS questions on how long each respondent had lived at his or her current address.

Each of the data sources used in the analysis has its advantages and disadvantages. Sensitivity analysis was conducted at key stages in the process

8. Let $l_{0}$ be the number of babies born each year in the life table population and $L_{0}$ be the number alive aged under one year. Then the chance that a baby born in a given year would be alive at the end of that year is $L_{0} / l_{0}$. The ratio obtained from the census is equal to $P_{0} / P_{t o t}$, where $P_{0}$ is the enumerated population aged under one year and $P_{t o t}$ is the total enumerated population. If the number of births in the year preceding the census is $B$ then the required crude birth rate is $B / P_{t o t}$, and assuming that $P_{0} / B=L_{0} / l_{0}$, we have $B=P_{0} l_{0} / L_{0}$ and the crude birth rate $=B / P_{\text {tot }}=P_{0}\left(l_{0} / L_{0}\right) / P_{\text {tot }}$.

9. Source: http://data.worldbank.org/country/congo-dem-rep [accessed 20 November 2012]. 
to justify the use of particular assumptions. Sensitivity analysis allowed us to derive a range of plausible estimates within which this study believes true figure of excess mortality lies. Table 1 summarises the data sources utilised in this study to derive the estimates.

\section{Results}

Results obtained under various assumptions and scenarios show that the size of the DRC population has been rapidly growing throughout the projection period (Table 2 and Figure 2). In most cases estimates of natural increase (births minus deaths), as well as the overall population growth, are higher for the counter-factual scenario than for the factual one. However, this is not the case under the lower assumptions where the opposite trend is observed mainly due to a set of irregular and extreme rates observed. In other words, the lower bound assumption set out to minimise the overall population growth by combining the highest observed mortality rates, the lowest observed fertility rates and the lowest observed net migration rates under the counterfactual projection scenario. This led to an overall lower population growth under the lower-bound assumption counter-factual scenario than under the factual one.

TABLE 2 Total number of births, deaths and net migration over 30 years (1984-2014)

\begin{tabular}{|c|c|c|c|c|}
\hline \multirow[t]{2}{*}{ Components } & Factual & $\begin{array}{c}\text { Counter- } \\
\text { factual }\end{array}$ & Factual & $\begin{array}{l}\text { Counter- } \\
\text { factual }\end{array}$ \\
\hline & \multicolumn{2}{|c|}{ Reference assumption } & \multicolumn{2}{|c|}{ INDEPTH assumption } \\
\hline Natural increase & $49^{\prime} 957^{\prime} 467$ & $51^{\prime} 399$ '889 & $54^{\prime} 641^{\prime} 144$ & $64^{\prime} 915^{\prime} 300$ \\
\hline Births & $73^{\prime} 892^{\prime} 720$ & $71^{\prime} 176^{\prime} 211$ & $77^{\prime} 866^{\prime} 633$ & $75^{\prime} 396^{\prime} 477$ \\
\hline Deaths & $23^{\prime} 935^{\prime} 253$ & $19^{\prime} 776^{\prime} 321$ & $23^{\prime} 225^{\prime} 489$ & $19^{\prime} 066^{\prime} 557$ \\
\hline Net migration & $-836^{\prime} 232$ & $26^{\prime} 855$ & $-836^{\prime} 232$ & $26^{\prime} 855$ \\
\hline \multirow[t]{2}{*}{ Population growth rate (per cent per year) } & 3.22 & 3.28 & 3.41 & 3.79 \\
\hline & \multicolumn{2}{|c|}{ «Lower» assumption } & \multicolumn{2}{|c|}{ «Upper» assumption } \\
\hline Natural increase & $39^{\prime} 942^{\prime} 471$ & $37^{\prime} 346^{\prime} 015$ & $61^{\prime} 596 \prime 839$ & $67^{\prime} 740^{\prime} 612$ \\
\hline Births & $62^{\prime} 584^{\prime} 498$ & $56^{\prime} 058^{\prime} 611$ & $84^{\prime} 668^{\prime} 574$ & $84^{\prime} 453^{\prime} 827$ \\
\hline Deaths & $22^{\prime} 642^{\prime} 027$ & $18^{\prime} 712^{\prime} 596$ & $23^{\prime} 071^{\prime} 735$ & $16^{\prime} 713^{\prime} 214$ \\
\hline Net migration & $-388^{\prime} 170$ & $448^{\prime} 458$ & $-388^{\prime} 170$ & $-143^{\prime} 850$ \\
\hline Population growth rate (per cent per year) & 2.78 & 2.65 & 3.67 & 3.89 \\
\hline
\end{tabular}


FIGURE 2. Population projection based on different assumptions for factual and counter-factual scenarios

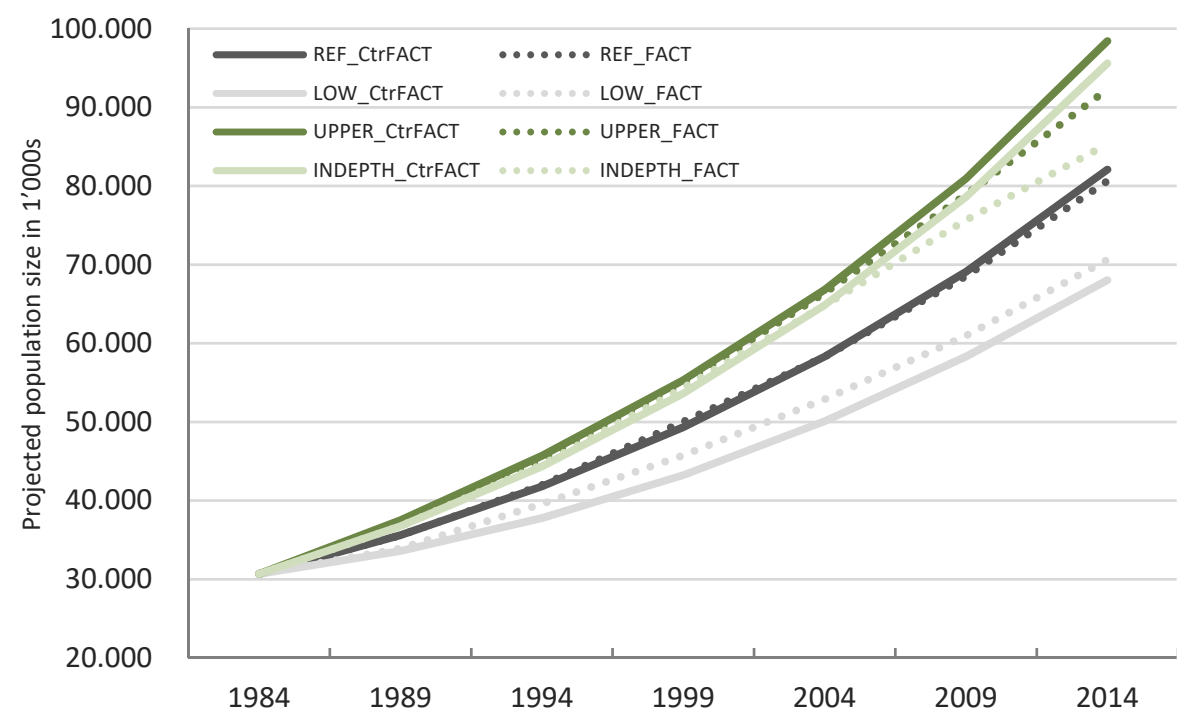

Notes: REF_CtrFACT: population projection under the reference assumption for the counter-factual scenario.

REF_FACT: population projection under the reference assumption for the factual scenario.

LOW_CtrFACT: population projection under the lower assumption for the counterfactual scenario.

LOW_FACT: population projection under the lower assumption for the factual scenario. UPPER_CtrFACT: population projection under the upper assumption for the counterfactual scenario.

UPPER_FACT: population projection under the upper assumption for the factual scenario.

INDEPTH_CtrFACT refers to population projection under the INDEPTH assumption for the counterfactual scenario.

INDEPTH_FACT: population projection under the INDEPTH assumption for the factual scenario.

To check the robustness of population size projected under the reference assumption, using observed average rates, it was important to compare with existing projections from alternative reputable sources. Table 3 shows DRC population projections as conducted in the mid-2010s by selected authoritative sources: the United Nations Population Division (2013), the United States Census Bureau (2010) and the DRC's Institut National de la Statistique (2014, pp. 69-71). These projections covered the period from 1984 to 2015 . The projected population size tends to be similar between the selected sources earlier in the projection cycle, but changes between 1989 and 1995, where there are more substantial differences. These differences in the projected population size decreased 
again between 1999 and 2009. The reference population projection conducted in this study is broadly consistent with that from these alternative sources. It is worth noting that, as expected, the further away the selected projections moved from the 1984 census, the less consistent they became. In other words, there is a relative decrease in accuracy of the projected population size with each increase of the projection period.

TABLE 3 Existing projections for population of Democratic Republic of the Congo from 1980 to 2015: population size in 1'000s

\begin{tabular}{|c|c|c|c|c|c|c|}
\hline 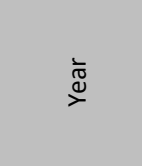 & 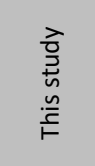 & 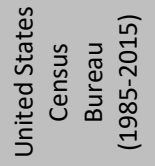 & 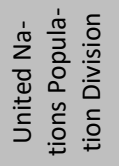 & 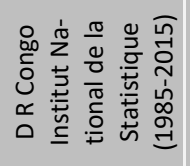 & 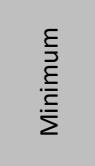 & 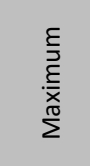 \\
\hline 1984 & $30^{\prime} 674$ & $33^{\prime} 348$ & $31^{\prime} 044$ & $30^{\prime} 674$ & $30^{\prime} 674$ & $33^{\prime} 348$ \\
\hline 1984-1989 & $35^{\prime} 578$ & $39^{\prime} 151$ & $36^{\prime} 406$ & & $35^{\prime} 578$ & $39^{\prime} 151$ \\
\hline 1989-1994 & $41^{\prime} 969$ & $46^{\prime} 705$ & $44^{\prime} 067$ & & $41^{\prime} 969$ & $46^{\prime} 705$ \\
\hline 1994-1999 & $50^{\prime} 004$ & $52^{\prime} 445$ & $49^{\prime} 626$ & $52 \prime 099$ & $49^{\prime} 626$ & $52^{\prime} 445$ \\
\hline 1999-2004 & $58^{\prime} 282$ & $60^{\prime} 698$ & $57^{\prime} 421$ & $60^{\prime} 566$ & $57^{\prime} 421$ & $60^{\prime} 698$ \\
\hline 2004-2009 & $68^{\prime} 539$ & $69^{\prime} 851$ & $65^{\prime} 966$ & $71^{\prime} 587$ & $65^{\prime} 966$ & $71^{\prime} 587$ \\
\hline $2009-2014$ & $80^{\prime} 631$ & $79^{\prime} 375$ & $75^{\prime} 190$ & $84^{\prime} 111$ & $75^{\prime} 190$ & $84^{\prime} 111$ \\
\hline
\end{tabular}

\section{Migration}

Figure 3 shows net migration in the DRC as provided by the United Nations Population Division from 1950 to 2010. The level of net migration fluctuated between zero and 250 '000 whilst remaining positive (meaning more people coming into the country than leaving) from 1950 to the early 1980s. This level then peaked between early 1990 and 1995 before dropping to negative figures (more people leaving the country than coming in). The period 1995-2005 was dominated by the impact of 1994 Rwandan genocide which saw more than a million people crossing the border from Rwanda to the DRC in 1995: a similar movement was observed almost five years later, but in the opposite direction from the DRC to Rwanda. From 2005 to 2010 the overall level of net international migration has been negative at the beginning of the period, trending to zero or slightly positive values toward the end of the decade. 
There do not seem to be reports on mortality in camps for displaced persons. But the limited evidence of mortality by region in the DRC does not support the view that mortality was higher in those regions where the camps were (Lindskog, 2016). Also, given that the mortality rates both direct and indirect estimates and scenarios included to model population change in this study are representative of the country as a whole, it is hard to conclude that excess mortality in camps would have a significant effect on the projected population size.

Figure 3 Net migration, both sexes combined (in 1'000s),

Democratic Republic of the Congo, 1950-1955 to 2005-2010

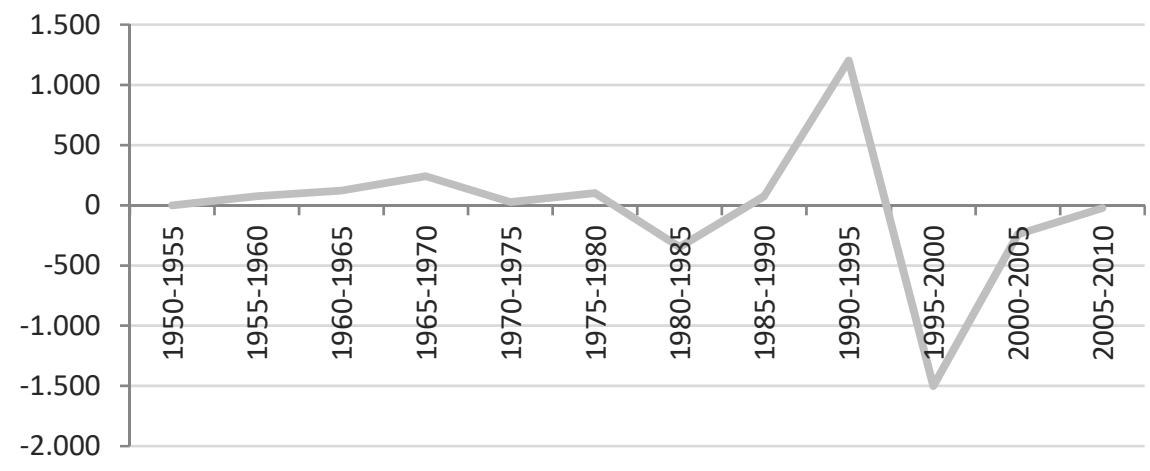

Source: United Nations Population Division, population estimates and projections section. Latest data available at https://population.un.org/wpp/DataQuery/ [accessed 6 July 2019].

\section{Fertility}

Like migration, fertility has not significantly influenced population change in the DRC for the projection period. Figure 4 shows that different studies produced similar age-specific fertility schedules although with some minor differences. Our 1985-1989 schedule, based on Shapiro and Tambashe (2003), is similar to those from intermediate surveys. MICS $(1995,2001)$ and DHS (2007) data provided age specific fertility obtained using direct methods in their respective surveys. Except for the years 1985-1989, it can be seen that early fertility levels tend to be higher than recent ones, implying a possible, though small, decline in fertility.

Overall, the number of births tended to be higher under the factual scenario compared to the counterfactual one. In the context of the DRC, this could be explained by the fact that the factual scenario projected more people of reproductive age (15 to 49 years old) than the counterfactual 
scenario, since having more people of reproductive age in the projection design impacts on the overall number of births. Historically, substantial differences in fertility levels in DRC have been associated with ethnicity but this has receded in importance since 2000 whilst education, particularly at secondary level and beyond has emerged as the most prominent factor (Shapiro and Tambashe 2017). From the current study, it is not possible to ascertain whether education is a significant factor in explaining the difference in births between the factual and counterfactual scenarios. Romaniuk $(2011$, p. 1) expressed that reproductive behaviour in the tropical Africa region or indeed the DRC is «metaphorically speaking, in a kind of no man's land where tensions between the forces resisting the transition and those propelling it are at an impasse with no resolution yet in sight». Based on findings from the current study, fertility has roughly remained at the same level throughout the period of armed conflict considered in this study.

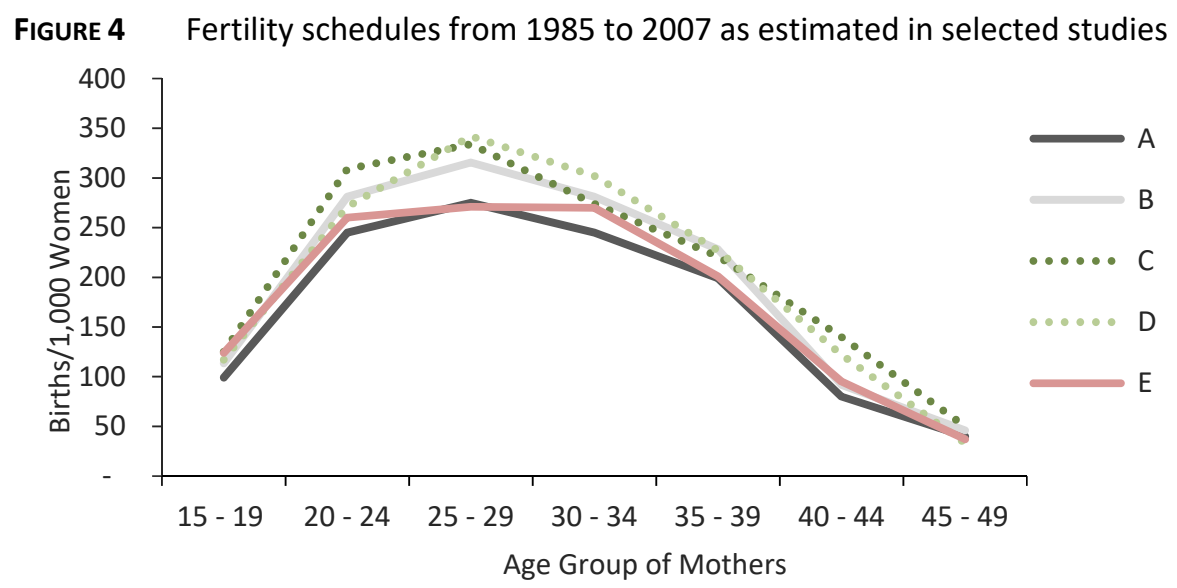

Sources: Multiple Indicator Cluster Surveys of the Democratic Republic of the Congo, 1995 and 2001; Demographic and Health Survey of the Democratic Republic of the Congo, 2007.

Notes: A- Reported births for 1985-89 see Shapiro \& Tambashe (2003, p. 55).

B- This study as derived by harmonising Shapiro \& Tambashe (2003) with DRC 1984 Census CBR. C- MICS 1995 Direct estimates.

D- MICS 2001 Direct estimates.

E- DHS 2007 Direct estimates.

DHS - Demographic and Health Survey, MICS - Multiple Indicator Cluster Survey.

To sum up the impact of armed conflict on the other all components of population change, neither net international migration, nor fertility have had a significant effect on population change over the period under study. Mortality is thus the key driver of the excess population change. However, 
it would not have been adequate to derive estimates of excess mortality without accounting for all three components of population change. Had this study considered shorter periods, net international migration could have a significant impact on population change; mainly due to significant influxes observed around key moments in the Rwandan civil war as shown in Figure 3.

\section{Derived excess mortality}

Table 4 provides a range of estimates of excess mortality between 1998 and 2007 based on the factual and the counter-factual scenarios using four sets of demographic assumptions: reference, «lower», «upper» and INDEPTH. The reference assumption produced an estimated number of deaths of 6'574'000 over the period under the counter-factual scenario, and 8' 150 ' 000 over the period under the factual scenario. The difference between these two figures implies the estimate of around 1'576'000 excess deaths associated with the conflict. The other three assumptions produced figures of excess deaths ranging from 1'042'000 to 1'933'000.

TABLE 4 Estimated number of deaths in the DRC between 1998 and 2007, under various assumptions

\begin{tabular}{|c|c|c|c|}
\hline Assumptions & $\begin{array}{c}\text { Overall deaths } \\
\text { with armed conflict } \\
\text { (Factual) (A) }\end{array}$ & $\begin{array}{l}\text { Overall deaths without } \\
\text { armed conflict } \\
\text { (Counter-factual) (B) }\end{array}$ & $\begin{array}{l}\text { Estimated deaths } \\
\text { attributed to armed conflict } \\
\text { (Excess mortality) (A-B) }\end{array}$ \\
\hline Reference & $8^{\prime} 150^{\prime} 000$ & $6^{\prime} 574^{\prime} 000$ & $1^{\prime} 576^{\prime} 000$ \\
\hline «Lower» & $8^{\prime} 019^{\prime} 000$ & $6^{\prime} 293^{\prime} 000$ & $1^{\prime} 726^{\prime} 000$ \\
\hline «Upper» & $6^{\prime} 883^{\prime} 000$ & $5^{\prime} 841^{\prime} 000$ & $1^{\prime} 042^{\prime} 000$ \\
\hline INDEPTH & $5^{\prime} 552^{\prime} 000$ & $3^{\prime} 619^{\prime} 000$ & 1'933'000 \\
\hline
\end{tabular}

\section{Implications and conclusion}

To sum up, findings from this study indicate that for the period 19982007 the excess mortality estimates associated with the DRC armed conflict range from a minimum of 1 million to a maximum of nearly 2 million deaths, under generally plausible assumptions. These can directly be 
compared with previous estimates from the IRC of 5.4 million deaths between years 1998 and 2007 (Coghlan et al., 2009) and Lambert and Lohlé-Tart's (2008) of just over 200'000 deaths in the same period.

This study, in line with those of Heuveline $(1998,2015)$, demonstrates the usefulness and value added of the demographic approach by providing plausible boundaries within which the excess mortality estimates are likely to lie. Similarly, Tabeau and Bijak (2006) analysed widely divergent pre-existing estimates of excess mortlity in Bosnia using demographic techniques. In this sense, the current paper fits within the tradition of the mainstream demography of armed conflict by adding a demographic perspective and rigour to the estimation process.

The approach adopted in the current paper has limitations that are associated with both the data and the methods. However, our forward population projections were compared against existing sources to assess their robustness. In addition, population size and the expectations of life at birth produced in this study were compared with more recent estimates produced by the United Nations and the World Bank. The recent surveys do not provide enough information at sub-national levels that would allow the estimation of the impact of the armed conflict in specific areas of the country. However, projected estimates of population size at national level are broadly consistent with those produced by agencies including the Institut National de la Statistique of the DRC and the United Nations Population Division.

The IRC's estimates of excess mortality have been widely adopted despite their limitations (Burnham et al., 2004; Pedersen 2009). The current paper expanded on the limitations associated with both the IRC's studies and the unpublished study by Lambert and Lohlé-Tart (2008) to highlight some of the issues and, where possible, suggest alternatives. The importance of considering competing analytical frameworks when assessing demographic consequences associated with armed conflicts has also been highlighted in this paper. Given that studies in this field deal with the human cost associated with armed conflicts, a highly sensitive issue, there is a potential for far-reaching consequences. This would include, for instance, the perception of victimhood and its impact on any prospects of lasting peace and state building in the medium to long-term (Eck, Hänni, 2013). Basing international policies on potentially contentious statistics risks feeding sentiments of revenge and contributing to the raising of tensions amongst populations in affected regions.

To prevent the contentious production or use of statistics associated with armed conflict, it is important that future interventions consider the following: 
- the identification of competing assessment tools and methods to select the most realistic upon which any intervention plan can be based;

- a comprehensive review of existing processes in selecting assessment tools and the effective communication of this review with interveners and the affected communities; and

- avoiding a focus on a single «best» estimate of excess death, given the uncertainties associated with the estimation process.

By doing this, it will be possible to produce figures that are less likely to feed controversy and foment future conflicts and sentiments of victimhood, even though the price to pay for that is to acknowledge the inevitable estimation errors. This will further contribute to the de-escalation of tensions, promote conditions for peace and strengthen state capacities in post-conflict situations.

\section{Acknowledgements}

A special thank you to Prof. Tony Chafer, Professor of French and African Studies at the University of Portsmouth. Tony has been very generous with his time and expertise as he provided valuable insights and comments on this paper's earlier drafts. The work on which this paper was based was funded by the United Kingdom Economic and Social Research Council (ESRC).

\section{References}

BESWICK J., MinOR E., (2014), New ORG Report: The UN and Casualty Recording: Good Practice and the Need for Action, Oxford Research Group.

Brunborg H., Tabeau E. (2005), «Demography of Conflict and Violence: An Emerging Field», European Journal of Population, pp.131-144, https://doi.org/10.1007/ s10680-005-6850-7.

BURCH T. K. (2018), «The Cohort-Component Population Projection: A Strange Attractor for Demographers», Springer C. (ed), Model-Based Demography. Demographic Research Monographs (A Series of the Max Planck Institute for Demographic Research), Springer, Cham., pp. 135-151, https://doi.org/10.1007/978-3-319-65433-1_ 10.

Burnham G., Roberts L., LAfta R., Garfield R., KhudhaiRI J. (2004), «Mortality before and after the 2003 Invasion of Iraq: Cluster Sample Survey», The Lancet, 364, pp. 1'857-1'864, https://doi.org/10.1016/S0140-6736(04)17441-2. 
Coghlan B., Brennan R. J., Ngoy P., Dofara D., Otto B., Clements M., Stewart T. (2006), "Mortality in the Democratic Republic of Congo: A Nationwide Survey», The Lancet, 367, pp. 44-51, https://doi.org/10.1016/S0140-6736(06)67923-3.

Coghlan B., Ngoy P., Mulumba F., Hardy C., Bemo N. V., Stewart T., Lewis J., Brennan R. (2009), Mortality in the Democratic Republic of Congo: An Ongoing Crisis, New York, International Rescue Committee.

Dwyer-Lindgren l., Cork M., Sligar A., Steuben K., Wilson K., Provost N., ..., Earl L. (2019), "Mapping HIV Prevalence in Sub-Saharan Africa between 2000 and 2017», Nature, pp. 189-193, https://doi.org/10.1038/s41586-019-1200-9.

ECK K., HÄNNı O. V. (2013), Male Victimhood in Armed Conflict, Retrieved from Political Violence @ a Glance: Expert Analysis on Violence and Its Alternatives.

Flahaux M.-L., SCHOumaker B. (2016), «Democratic Republic of the Congo: A Migration History Marked by Crises and Restrictions", Migration Information Source, https://www.migrationpolicy.org/article/democratic-republic-congo-migrationhistory-marked-crises-and-restriction.

Heuveline P. (1998), “'Between One and Three Million': Towards the Demographic Reconstruction of a Decade of Cambodian history (1970-79)", Population Studies, 52, pp. 49-65, https://doi.org/10.1080/0032472031000150176.

Heuveline P. (2015), «The Boundaries of Genocide: Quantifying the Uncertainty of the Death Toll during the Pol Pot Regime in Cambodia (1975-79)", Population Studies: A Journal of Demography, pp. 201-218, https://doi.org/10.1080/00324728.2015. 1045546.

HINDE A. (1998), Demographic Methods, London, Arnold.

Human Rights Watch (1998), Les Libertés Bafouées, Retrieved from Human Rights.

Human Security Report (2011), Human Security Report 2009/2010: The Causes of Peace and The Shrinking Costs of War, New York, Oxford University Press.

INDEPTH Network (2004), INDEPTH Model Life Tables for Sub-Saharan Africa, Aldershot, Ashgate Publishing Limited.

Institut National de la Statistique (1994), Profil de la femme au Zaire, Kinshasa, Ministère du Plan.

Institut National de la Statistique (2014), Annuaire statistique 2014, Kinshasa, Ministère du Plan et Révolution de la Modernité.

International Crisis Group (1998), Congo at War: A Briefing on the Internal and External Players in the Central African Conflict, Retrieved March 15, 2012.

KANE D. (2007), The Lancet Surveys of Mortality in Iraq, June.

Kapend R., BiJaK J., Hinde A. (2013), «The D R Congo Conflict (1998-2004): Assessing Excess Deaths Based on War and Non-War Scenarios", XXVII IUSSP International Population Conference, Busan, Springer. 
LAMBert A., LohlÉ-TART L. (2008), D R Congo's Excess Death Toll during the 1998-2004 Conflicts: An Excess Deathestimate Based Scientifically on Demographic Methods, Retrieved May 18th, 2010.

LINDSKog E. E. (2016), "The Effect of War on Infant Mortality in the Democratic Republic of Congo», BMC Public Health, 16, pp.1-10, https://doi.org/10.1186/ s12889-016-3685-6.

Matthew R. (2012), «Demography, Climate Change, and Conflict», Goldstone J. A., Kaufmann E. P., Toft M. D. (eds), Political Demography: How Population Changes Are Reshaping International Security and national Politics, Oxford, Oxford University Press, pp. 133-146.

Ministère du Plan et Reconstruction Nationale RDC (1995), Situation des enfants et des femmes au Zaïre, Kinshasa.

Moultrie T. A., Dorrington R. E., Hill K., Timaeus I. M., ZaBA B. (2013), Tools for Demographic Estimation, Paris, International Union for the Scientific Study of Population.

NaNiUZeYı M. E. (1999), "The State of the State in Congo-Zaïre: A Survey of the Mobutu Regime», Journal of Black Studies, pp. 669-683, https://doi.org/10.1177/ 002193479902900506.

Ndikumana L., BoyCE J. (1998), «Congo's Odious Debt: External Borrowing and Capital Flight in Zaire», Development and Change, pp. 195-217, https://doi.org/10.1111/ 1467-7660.00076.

Newell C. (1988), Methods and Models in Demography, Chichester, John Wiley \& Sons.

Nzongola-Ntalaja G. (1970), "The Bourgeoisie and Revolution in the Congo», Journal of Modern African Studies, pp. 511-530, https://doi.org/10.1017/S0022278X00023 879.

Nzongola-Ntalaja G. (2002), The Congo from Leopold to Kabila: A People History, London, Zed Books.

Participants, Democratic Republic of the Congo (2003), Inter-Congolese Negotiations: The Final Act (Sun City Agreement), Peace Agreement, Sun-City.

Pedersen J. (2009), Re-Examining Mortality from the Conflict in the Democratic Republic of Congo, 1998-2006, Geneva, The Health and Nutrition Tracking Service (HNTS).

Price M., Gohdes A., Ball P. (2014), Updated Statistical Analysis of Documentation of Killings in the Syrian Arab Republic, pp. 1-25.

Prunier G. (2009), From Genocide to Continental War: The 'Congolese' Conflict and the Crisis of Contemporary Africa, London, Hurst \& Company.

Research Directorate, Immigration and Refugee Board, Canada (1997), Zaïre : I'exercice du pouvoir en région, April 1, Retrieved from Refworld: https://www.refworld. org/docid/3ae6a8258.html. 
ReYNTJENS F. (1999), «Briefing: The Second Congo War: More than a Remake», African Affairs, pp. 241-250, https://doi.org/10.1093/oxfordjournals.afraf.a008010.

Roberts L., Ngoy P., Mone C., lubula C., Mweze L., Zantop M., Despines M. (2003), Mortality in the Democratic Republic of Congo: Results from a Nationwide Survey, New York, International Rescue Committee.

Romaniuk A. (2011), "Persistence of High Fertility in Tropical Africa: The Case of the Democratic Republic of the Congo", Population and Development Review, pp. 1-28, https://doi.org/10.1111/j.1728-4457.2011.00388.x.

Sciencemag (2010), Science Insider, Retrieved from News Science Mag.

Shapiro D., TAMBashe B. O. (2017), «Recent Fertility Changes in the Democratic Republic of the Congo", N-IUSSP, https://doi.org/10.11564/31-1-959.

Siege J. S., SWANSon D. A. (2008), "Methods Materials Demography Second Edition», SIEGEL J. S., SWANSON D. A., Introduction, United Kingdom, Emerald, pp. 1-8, https:// doi.org/10.1016/B978-012641955-9/50035-7.

Stearns J., Verweijen J., BaAz M. E. (2013), The National Army and Armed Groups in the Eastern Congo Untangling the Gordian Knot of Insecurity, Retrieved from Rift Valley Institute/Usalama Project.

Tabeau E., BiJak J. (2006), «War-Related Deaths in the 1992-1995 Armed Conflicts in Bosnia and Herzegovina: A critique of previous Estimates and Recent Results», Brunborg H., Tabeau E., Urdal H. (eds), The Demography of Armed Conflict, Dordrecht, Springer, pp. 217-244, https://doi.org/10.1007/978-1-4020-5135-7_11.

Unicef (2004), Epidemiological Facts Sheets on HIV/AIDS and Sexually Transmitted Infections, Demovratic Republic of the Congo.

United Nations (1983), Manual X Indirect Techniques for Demographic Estimation, New York, Departement of International Economic and Social Affairs.

United Nations News (2019), UN Working to Prevent Attacks on Civilians in Eastern $D R$ Congo, November 26, Retrieved from UN News.

United Nations Office of the High Commissioner for Human Rights (2010), Report of the Mapping Exercise Documenting the Most Serious Violations of Human Rights and International Humanitarian Law Committed within the Territory of the Democratic Republic of the Congo between March 1993 and June 2003, Retrieved March 3, 2012, from UNHCR The UN refugee Agency.

United Nations Population Division (2013), Population Division, Population Estimates and Projections Section, Retrieved from Department of Economic and Social Affairs Population/World Population Prospects.

United Nations Security Council (1994), Security Council Resolution S/RES/955, Retrieved March 4, 2012, from UNHCR The UN Refugee Agency.

United Nations Security Council (1999a), Resolution 1258 (1999) Adopted by the Security Council at its 4032nd meeting on 6 August 1999. Security Council. 
United Nations Security Council (1999b), RESOLUTION 1279 (1999) Adopted by the Security Council at its 4076th meeting' on 30 November 1999, Retrieved February 15, 2012, from UNHCR The UN Refugee Agency.

United Nations Security Council (2014), Security Council Resolutions, United Nations. United Nations High Commission for Refugees (1998), UNHCR CDR Background Paper on Refugees and Asylum Seekers from Rwanda, Retrieved February 14, 2011, from UNHCR The UN Refugee Agency.

Urdal H. (2012), "Youth Bulges and Violence», Goldstone J. A., KaufMann E. P., TofT M. D. (eds), Political Demography: How Population Chnages Are Shaping International Security and national Politics, Oxford, Oxford University Press. pp. 117-132.

United States Census Bureau (2010), International Data Base Population Estimates and Projections Methodology, Retrieved from The US Census Bureau.

Verpoorten M. (2005), «The Death Toll of the Rwandan Genocide: A Detailed Analysis for Gikongoro», Population, pp.331-367, https://doi.org/10.3917/pope.504. 0331.

WILSON T. (2010), "Model Migration Schedules Incorporating», Demographic Research, pp. 191-222, https://doi.org/10.4054/DemRes.2010.23.8.

World Bank (2018), Microdata Library, Retrieved from The World Bank. 